\section{Dysregulation of protein modification by ISG15 results in brain cell injury}

\author{
Kenneth J. Ritchie, ${ }^{1}$ Michael P. Malakhov, ${ }^{1}$ \\ Christopher J. Hetherington, ${ }^{1}$ Liming Zhou, ${ }^{1}$ \\ Marie-Terese Little, ${ }^{1}$ Oxana A. Malakhova, ${ }^{1}$ Jack \\ C. Sipe, ${ }^{1}$ Stuart H. Orkin, ${ }^{2}$ and Dong-Er Zhang ${ }^{1,3}$ \\ ${ }^{1}$ Department of Molecular and Experimental Medicine, \\ MEM-L51, The Scripps Research Institute, 10550 North \\ Torrey Pines Road, La Jolla, California 92037, USA; ${ }^{2}$ Division \\ of Hematology-Oncology, Children's Hospital and Dana \\ Farber Cancer Institute, Howard Hughes Medical Institute, \\ Harvard Medical School, Boston, Massachusetts 02115, USA
}

UBP43 (USP18) is a protease that removes the ubiquitinlike modifier ISG15 from conjugated proteins. Here we present the first report of dysregulation of protein ISG15 modification by the generation of UBP43 knockout mice. In the absence of UBP43, brain tissue showed an elevated level of ISG15 conjugates, and cellular necrosis was evident in the ependyma. Such disruption of the blood-brain barrier resulted in severe neurologic disorders. These results demonstrate that UBP43 plays a critical role in maintaining the homeostatic balance of ISG15-conjugated protein, and that regulation of cellular levels of ISG15 protein modification is essential for brain cell function.

Received May 28, 2002; revised version accepted July 12, 2002.

Protein modification by ubiquitin and ubiquitin-like proteins regulates a host of important cellular functions (Hochstrasser 2000; Hicke 2001; Pickart 2001). Aberrations in protein ubiquitination are associated with diseases such as Parkinson's, cervical cancer, von Hippel Lindau syndrome, Liddle syndrome (pseudoaldosteronism), and Angelman syndrome (Schwartz and Ciechanover 1999). ISG15 (interferon-stimulated gene 15) is an ubiquitin-like protein that contains a tandem repeat of ubiquitin-like domains, exhibits a marked homology to ubiquitin and crossreactivity with a ubiquitin antiserum (also known as ubiquitin crossreacting protein, UCRP; Haas et al. 1987). ISG15 gene expression is induced by interferons (Farrell et al. 1979; Blomstrom et al. 1986). Increased levels of both free and protein conjugated ISG15 have thus been reported in various cell lines and human subjects following interferon treatment and viral infection (Loeb and Haas 1992; D'Cunha et al. 1996b). Free ISG15 is reported to be an interferon-induced cytokine with immunomodulatory characteristics due to its ability to stimulate the proliferation of NK cells

[Key Words: interferon; ubiquitin; knockout] ${ }^{3}$ Corresponding author.

E-MAIL dzhang@scripps.edu; FAX 858-784-9593.

Article and publication are at http://www.genesdev.org/cgi/doi/10.1101/ gad.1010202.
(D'Cunha et al. 1996a). In contrast to ubiquitination, however, the consequences of the addition of ISG15 to a target protein (ISGylation) remain unknown, although speculation exists that ISG15 conjugation may alter the biologic activities of modified proteins in common with other ubiquitin-like proteins such as SUMO-1 (Jentsch and Pyrowolakis 2000).

We have cloned a $43-\mathrm{kD}$ ISG15-specific protease, termed UBP43, which, in common with the deubiquitinating enzyme family, contains two highly conserved domains (Cys and His boxes; Hochstrasser 1996; Wilkinson 1997; D'Andrea and Pellman 1998; Liu et al. 1999; Gilchrist and Baker 2000; Schwer et al. 2000; Malakhov et al. 2002). Further investigation into this gene has revealed that it is responsive to bacterial lipopolysaccharides via interferon regulatory factor-3 (IRF-3) and to interferons via the Jak/stat pathway (Li et al. 2000; Kang et al. 2001; Malakhova et al. 2002). UBP43 has also been reported to be induced by viral infection (Zhang et al. 1999).

The selective ability of UBP43 to remove ISG15 from proteins indicates that UBP43 plays a vital role in the regulation of ISGylation. Further, in consideration of UBP43 and ISG15 both being strongly induced by interferons, both proteins may play important roles in the cellular response to infection. To investigate the function of protein ISGylation we have produced UBP43 knockout mice. UBP43-deficient mice are viable, but show phenotypes indicative of neurologic abnormalities with the development of hydrocephalus. Homozygous brain tissue contains increased levels of ISG15-conjugated proteins. Ultrastructural studies reveal that in the absence of UBP43, brain ependymal cells undergo necrotic cell death prior to the development of hydrocephalus. This result indicates that the regulation of protein ISGylation by UBP43 is a critical biochemical event for cellular viability.

\section{Results}

\section{Disruption of the mouse UBP43 gene}

To disrupt one allele of $U B P 43$ in mouse ES cells a region of the UBP43 gene containing exons 2-4 was modified as shown in Figure 1a, thus removing the translation start codon and the Cys domain of UBP43. This construct also contained the bacterial neomycin and the $\beta$-galactosidase (Lac-Z) genes as selection and expression markers, respectively. Chimeric animals were produced by injection of heterozygous ES cells into C57BL/6 blastocyststage embryos, and transmission through the germline was determined by breeding with wild-type C57BL/6 mice.

\section{UBP43-deficient mice develop hydrocephalus}

Heterozygous $\left(U B \mathrm{P}_{4} 3^{+/-}\right)$mice appeared normal, and interbred to produce UBP43 knockout mice $\left(U B P 43^{-/-}\right)$. Genotyping was carried out by Southern blot (Fig. 1a, probe B). Figure $1 \mathrm{~b}$ shows a representative Southern blot of DNA from several wild-type, heterozygous, and homozygous offspring. Western blot analysis also confirmed the absence of UBP43 expression (Fig. 1c). These 


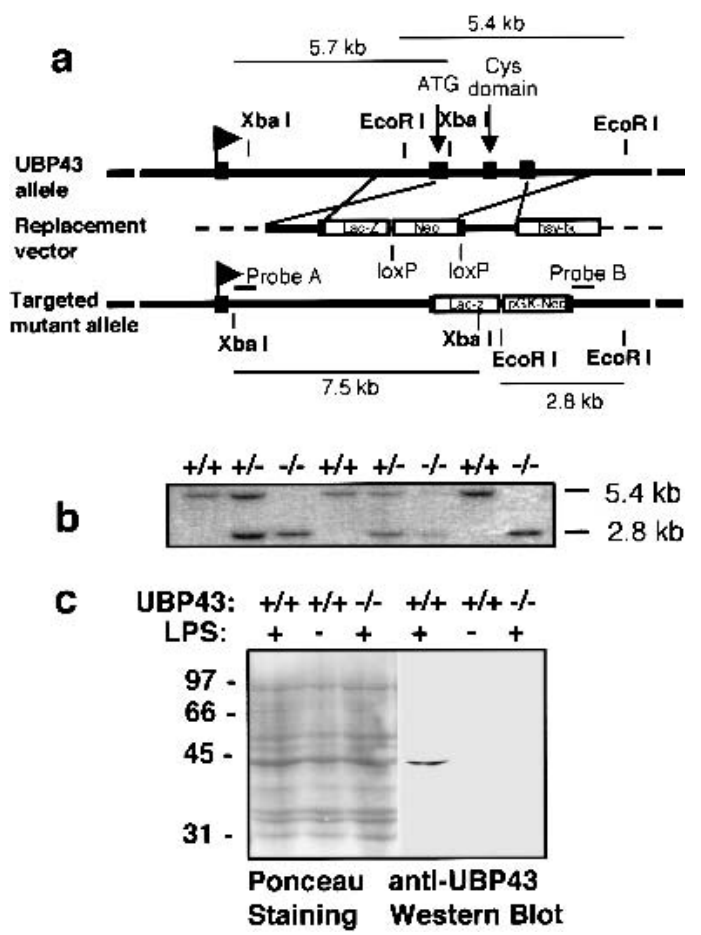

Figure 1. (a) Strategy of UBP43 knockout. Targeted disruption of the UBP43 locus was performed by replacement of exons 2-4 (including the translation start codon and the UBP43 Cys domain) with the Lac- $Z$ reporter gene. The reporter gene was consequently under the control of UBP43 regulatory elements, allowing identification of UBP43-expressing cell types. (b) Southern blot to identify UBP43 knockout mice (see Materials and Methods). Generation of a single band at $5.4 \mathrm{~kb}$ indicates a wild-type mouse $\left(\mathrm{UBP}_{4} 3^{+/+}\right)$, while the presence of a $2.8-\mathrm{kb}$ band indicates a homozygous genotype $\left(U B P 43^{-/-}\right)$. Heterozygotes $\left(U B P 43^{+/-}\right)$are identified from the presence of both bands. (c) Confirmation of UBP43 knockout. Both $U B P 43^{-/-}$and $\mathrm{UBP}_{43^{+/+}}$mice were injected intraperitonealy with $15 \mu \mathrm{g} / \mathrm{g}$ body weight of LPS. Twenty-four hours later, mice were sacrificed and thymi recovered. Western blot analysis was then undertaken (see Materials and Methods).

mice were born at the expected Mendelian ratio of 1:2:1 of $U B P 43^{+/+}, U B P 43^{+/-}, U B P 43^{-/-}(\mathrm{n}=104)$, indicating that $U B P 43$ is not critical for embryonic development. Despite being born at the expected ratio, UBP43-/- mutants did, however, display a reduced life expectancy relative to $U B P 43^{+/+}$and $U B P 43^{+/-}$mice (Fig. 2a). Prior to death, UBP43 ${ }^{-1-}$ mice displayed a variety of abnormal behaviors, including convulsions, tremor, loss of balance, rolling, and repeated tight circling, consistent with neurologic abnormalities. Therefore, brains of $U B P 43^{-/-}$ and $U B P 43^{+/+}$mice were dissected and examined (see Fig. 2b,c). UBP43 ${ }^{-/-}$mice displayed hydrocephalus, as indicated by the bilateral enlargement of the lateral ventricles and the third ventricle and associated thinning of the cerebral cortex. Such ventricular enlargement was also accompanied by intracerebral haemorrhage and bloody cerebrospinal fluid (CSF). UBP43 ${ }^{-1-}$ mouse brains did not have dilation of the fourth ventricle. Brains of littermate $\mathrm{UBP}_{4} 3^{+/+}$and $U B \mathrm{P}_{4} 3^{+/-}$control mice were normal (Fig. 2b,c; heterozygous not shown).
Disruption of the UBP43 gene results in a noncommunicating (obstructive) hydrocephalus

Hydrocephalus occurs as a consequence of the abnormal accumulation of CSF in the cranial cavity, resulting in dilation of the ventricular system. Such accumulation of CSF may occur due to an obstruction in the CSF circulation between ventricles via stenosis (occlusion) of the aqueduct of Sylvius, a decrease in the absorption of CSF at the arachnoid villi, and/or over secretion of CSF from the choroid plexus epithelial cells that are the principal producers of CSF within the ventricular system (Sarnat 1995; Lindeman et al. 1998; McAllister and Chovan 1998).

To define at which point during mouse development disruption of the UBP43 gene resulted in hydrocephalus, brains from day 17 UBP43-/- embryos, 2-d-old, and 14d-old $U B P 43^{-1-}$ mice were examined. Hydrocephalus was first noted at day 14 after birth.

To define the mechanism by which hydrocephalus occurs in UBP43 ${ }^{-/-}$mice, complete brains from UBP43 ${ }^{-/-}$ and $U B P 43^{+/+}$mice were serially sectioned, stained, and examined. UBP43 $3^{-/-}$mice consistently developed complete stenosis of the aqueduct of Sylvius (Fig. 3b). In contrast, the entire CSF drainage pathway was clear and patent in $\mathrm{UBP}_{4} 3^{+/+}$and $U B P 43^{+/-}$mice (Fig. $3 \mathrm{a} ; \mathrm{UBP}_{4} 3^{+/-}$ not shown). Therefore, disruption of the UBP43 gene results in a noncommunicating hydrocephalus.

\section{UBP43 is selectively expressed in brain ependymal cells}

The occurrence of hydrocephalus within UBP43-deficient mice was unexpected in consideration of previous investigations reporting that UBP43 RNA was not detectable in brain tissue by Northern blot (Liu et al. 1999). Therefore, to investigate UBP43 expression within the brain a histochemical investigation into reporter gene expression was undertaken. Significantly, reporter gene

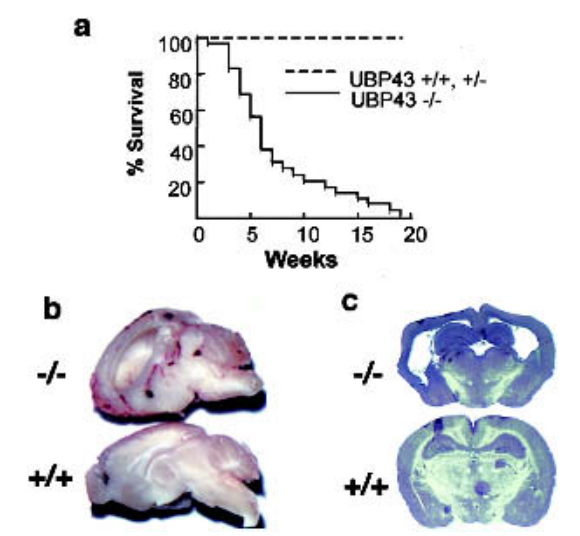

Figure 2. Phenotypes of UBP43 knockout mice. (a) UBP43-/mice show a reduced survival relative to $U B P 43^{+/+}$and $U B P 43^{+/-}$littermates $(\mathrm{n}=32$ homozygotes). (b) Image of a midsagittal section through the brains of $\mathrm{UBP} \mathrm{3}^{-/-}$and $\mathrm{UBP}^{-3^{+/+}}$ mice. The $U B P 43^{-/-}$mouse shows a distension of the lateral ventricle and intracerebral haemorrhage. $(c)$ Light microscope analysis of coronal sections through the caudal regions of 7-wkold $U B P 43^{-/-}$and $U B P 43^{+/+}$mice. The lateral ventricles and the third ventricle of the UBP43 ${ }^{-/-}$mouse are significantly enlarged when compared with the wild-type littermate control. 


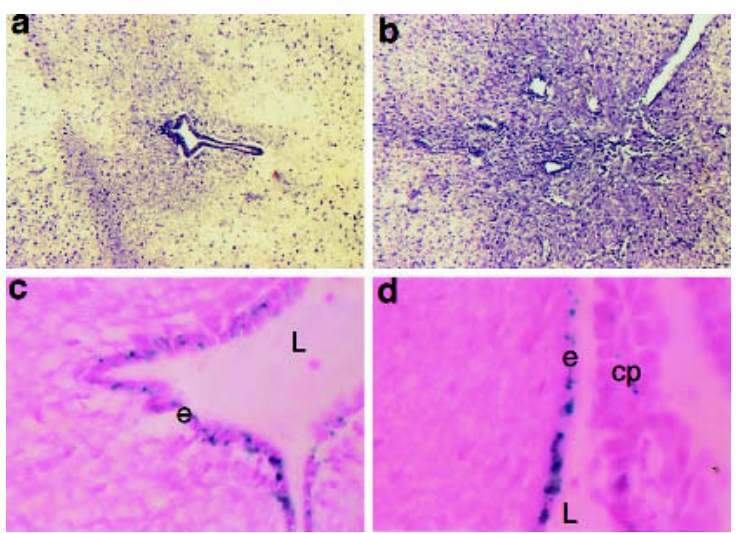

Figure 3. Light microscopic analysis of the aqueduct of 7-wkold littermate $U B P 43^{+/+}(a)$ and $U B P 43^{-/-}$mice $(b)$. The aqueduct of Sylvius of the $U B P 43^{+/+}$mouse is patent, and the wall of the aqueduct can be seen to be lined by cuboidal ependymal cells. In contrast, the aqueduct of Sylvius of the UBP43-/mouse is absent with no histologic trace of ependymal cells. Magnification, $a, b, 200 \times$. Light microscopic analysis of reporter gene expression within the aqueduct $(c)$ and the lateral ventricles $(d)$ of $U B P 43^{-/+}$mice. 5-Bromo 4-chloro-3-indolyl $\beta$-Dgalactopyranoside (X-gal) staining shows intense reporter gene expression in the ependymal cells of both the aqueduct and the ventricle. No staining was observed in $\mathrm{UBP}_{4} 3^{+/+}$mice (not shown). L, lumen of the ventricle; e, ependymal; $\mathrm{cp}$, choroid plexus. Magnification, $c, d, 1000 \times$.

expression was localized to the epithelial ependymal cells (Fig. 3c,d). These cells form a single uninterrupted layer of ciliated squamous to columnar epithelial cells that line both the ventricles and the aqueduct of the brain. Reporter gene expression was absent from negative controls of wild-type brain sections (data not shown). Importantly, the presence of reporter gene expression within the ependymal cells of $U B P 43^{+/-}$mice indicates that UBP43 is expressed in these cells under normal physiologic conditions. Furthermore, deletion of the $p G K-N e o$ gene by breeding with transgenic mice expressing Cre recombinase had no effect on the expression pattern of the reporter gene.

Increased levels of protein ISGylation and ependymal cell necrosis is evident prior to development of hydrocephalus

In consideration of UBP43 being an ISG15-specific protease, an immunohistochemical investigation was performed to delineate the levels of ISG15 in ependymal cells of $U B P 43^{-1-}$ mice. Greatly increased levels of ISG15 staining, relative to ISG15 staining in $U B P 43^{+/+}$, was observed in both ependymal cells and general brain tissue of the UBP43-/- mice (Fig. 4a,b). Immunohistochemical staining does not, however, have the ability to differentiate between free and conjugated forms of ISG15. Therefore, Western blot analysis was performed, using antiISG15 antiserum, on various regions dissected from $U B P 43^{+/+}, U B P 43^{+/-}$and UBP43- $3^{--}$brains. The results presented in Figure $4 \mathrm{c}$ show a significant increase of ISG15 protein conjugates in all UBP43 ${ }^{-/-}$brain tissues. In contrast, ISG15-conjugated proteins were not detect- able in $U B P 43^{+/+}$and $U B P 43^{+/-}$brain tissue. This data demonstrates that disruption of the UBP43 gene results in an elevated level of ISG15 protein conjugates within the mammalian brain.

To further investigate the ependymal lining of $U B P 43^{-/-}$mice, immunohistochemistry and ultrastructural studies of prehydrocephalic mice (12 d old) were undertaken to delineate both the level of ISG15 and the ependymal morphology prior to ventricular distension as determined by careful examination of brain tissue prior to processing. In contrast to wild-type ependyma (Fig. 5a) increased levels of ISG15 are seen in the ependyma of prehydrocephalic UBP43-/- mice (Fig. 5b). Upon ultrastructural examination of UBP43-/- ependyma, intermittent ventricular ependymal cells were observed to have disrupted plasma membranes resulting in leakage of intracellular contents into the lumen of the ventricle (Fig. 5d). In contrast, ependymal cells of $U B P 43^{+/+}$littermate control mice appeared normal (Fig. 5c). Such cellular lysis is characteristic of necrosis. Additionally, the nucleus of one of the lysed cells in Figure $5 \mathrm{~d}$ is observed to be intact, and lacks the characteristic nuclear condensation associated with apoptosis, thus confirming the occurrence of necrotic ependymal cell death. Ependymal cell death, via necrosis, is therefore evident prior to the development of hydrocephalus in UBP43-deficient mice. Such stress may also lead to an increase in free ISG15 production as shown in Figure 4c.

We have provided evidence that UBP43 has an essential function in the postnatal brain in the regulation of
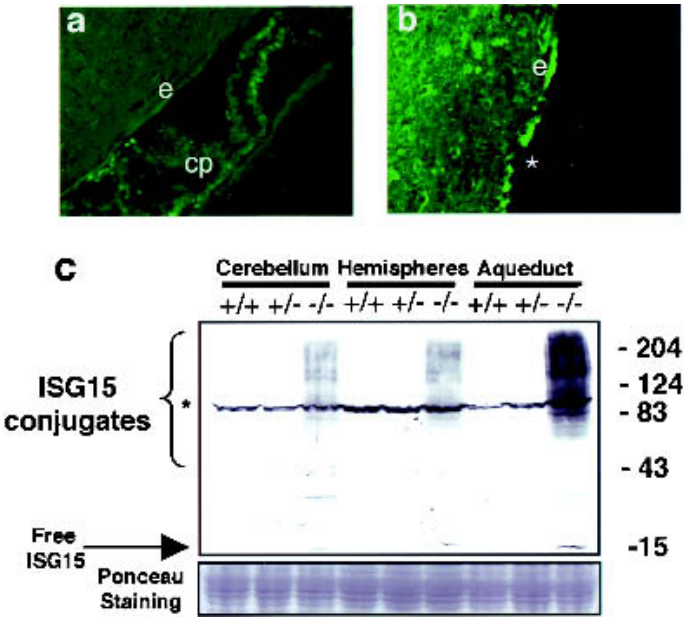

Figure 4. Immunohistochemistry of lateral ventricle ependymal cells in $\mathrm{UBP}_{4} 3^{+/+}$and $U B P 43^{-/-}$mice. Coronal sections through the caudal region of the forebrain of 7-wk-old $U B P 43^{+/+}$ and $U B P 43^{-/-}$mice were stained with ISG15 antibody. (a) Ependymal cells and choroid plexus of $\mathrm{UBP}_{4} 3^{+/+}$are largely devoid of ISG15 staining in comparison to the ependymal cells of $U B P 43^{-1-}$ mice $(b)$. e, ependymal cells; $\mathrm{cp}$, choroid plexus. Areas where ependymal cells have been lost are marked ${ }^{\star}$. Magnification, $a, b, 400 \times$. (c) Western-blot analysis of total protein from cerebellum, cerebral hemispheres, and aqueductal region of $U B P 43^{+/+}, U B P 43^{+/-}, U B P 43^{-/-}$mice with polyclonal antiISG15 antibodies. Twenty micrograms of protein from each dissected brain area were separated by SDS-PAGE, blotted, and probed as described (see Materials and Methods). ${ }^{*}$ indicates a nonspecific band. 

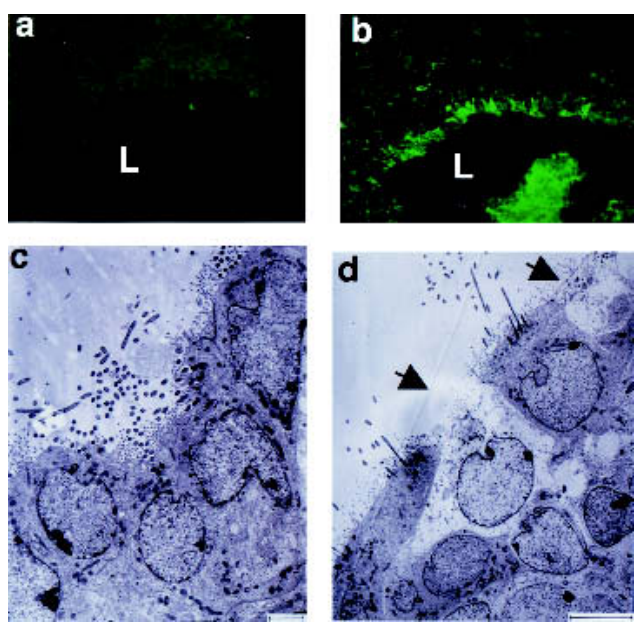

Figure 5. Immunohistochemical and ultrastructural analysis of ependymal cells lining the ventricle of 12 -d-old $U B P 43^{-/-}$and $U B P 43^{+/+}$littermate mice prior to the development of hydrocephalus. In contrast to the ependymal cells of the wild-type $(a)$, lateral ventricle ependymal cells of $U B P 43^{-/-}$mice $(b)$ are found to have increased levels of ISG15. L, lumen of the ventricle. Magnification, $a, b, 400 \times$. Necrosis is not evident in $\mathrm{UBP}_{4} 3^{+/+}$ littermate control mice $(c)$. Ependymal cell necrosis is observed in $U B P 43^{-/-}$mice $(d)$. Cells that have undergone necrosis are indicated with arrows. Bar, $c, 2 \mu \mathrm{m} ; d, 5 \mu \mathrm{m}$.

ISG15 conjugation. Elimination of UBP43 leads to increased levels of protein ISGylation in vivo. The resulting necrosis of ependymal cells leads to aqueductal stenosis and the development of hydrocephalus. Compression of vital central nervous system structures is envisaged to result in the premature death of UBP43deficient mice.

Infection by certain viruses causes hydrocephalus (Johnson et al. 1967; Ahdab-Barmada et al. 1982; Tardieu and Weiner 1982; Barton and Mets 2001). Interestingly, ependymal cell necrosis also occurs following intracerebral inoculation of mice with a naturally selected temperature-sensitive mutant of vesicular stomatitis virus (VSV). Such mice develop ependymal cell necrosis in both the aqueduct and the lateral ventricles as early as 2 d postinoculation, but do not develop hydrocephalus until 10 d postinoculation (Ahdab-Barmada et al. 1982). UBP43 and ISGylation are induced by viral infection. However, in the absence of such infection (littermate $U B P 43^{+/+}$mice show no induction of UBP43), it may be postulated that UBP43 disruption results in a loss of function in the homeostatic regulatory mechanism that controls basal levels of ISG15 conjugation. Therefore, proteins critical to normal cellular function may become and/or remain conjugated to ISG15, elevating intracellular levels of ISG15 conjugates and fatally altering the cells overall physiology. Given that ISGylation is increased upon viral infection, it is possible that the absence of UBP43 mimics the effect of virally induced ependymal cell necrosis and, therefore, also results in hydrocephalus.

UBP43 is the only currently known ISG15-specific protease. Logically, and in common with other cellular pathways, the possibility exists that cells may possess alternative pathways to remove ISG15 from protein conjugates. Other ISG15-specific proteases may exist with unique protein-ISG15 substrate specificities. Cell-specific ISG15 protease expression and cellular localization may also determine the activities of other yet-to-be-identified ISG15-specific proteases. However, in consideration of the striking difference in relative levels of ISGylation in $U B P 43^{-/-}$and $U B P 43^{+/+}$mice reported in this study, the presence of a second cellular ISG15-specific protease with equivalent substrate specificities within the brain appears unlikely. Furthermore, ISG15 is synthesized as an inactive $17-\mathrm{kD}$ precursor, and processed into ISG15 with the removal of eight amino acids from its C-terminal by a processing protease (Knight et al. 1988). Because protein ISGylation occurs efficiently in UBP43 knockout mice, UBP43 is at least not fully responsible for endogenous ISG15 processing from its 17 $\mathrm{kD}$ precursor. The apparent lack of alternative enzymes capable of ISG15 removal and the subsequent cell death noted emphasizes the importance of UBP43 in regulating levels of ISG15-conjugated proteins within specific cells. Indeed, the biologic effects of conjugation by ubiquitinlike proteins, and therefore the importance of their regulation, are just beginning to be defined. Sumoylation, for example, has been shown to have two general effects: an alteration in the affinity of the SUMO-conjugated RanGAP1 and promyelocytic leukemia protein (PML) towards the nuclear pore complex and nuclear body, respectively, and the ability to compete with ubiquitin for conjugation to both I $\mathrm{B} \alpha$ and MDM2 proteins (Muller et al. 2001). Nedd8-ylation has been shown to be involved in the regulation of protein degradation pathways involved in cell cycle progression and morphogenesis (Kawakami et al. 2001; Lyapina et al. 2001; Schwechheimer et al. 2001; Tateishi et al. 2001). Recently, the influenza B virus protein NS1B has been reported to selectively inhibit ISGylation via UBE1L, suggesting a role for ISG15 modification in viral defense (Yuan and Krug 2001).

Speculation exists as to why ependymal cell death results in hydrocephalus. In view of the basic function of ependymal cells to serve as a barrier to excessive volumes of CSF movement into the surrounding brain tissue, ependymal necrosis is thought to contribute to subependymal edema (Baumgartner et al. 1982). Such an increase in extraventricular pressure consequently forces the walls of the aqueduct together, producing the stenosis noted (Raimondi et al. 1976). Alternatively, ependymal cell death and the resultant destruction of aqueductal architecture may result in a stenotic lesion due to increased contact between subependymal elements in an attempt to prevent CSF leakage into the surrounding neuropil (Baumgartner et al. 1982). Finally, it is interesting to note that the ependymal cell layer is thought to be one site of stem cell production within the brain (Johansson et al. 1999; Rietze et al. 2001). Therefore, due to the dysfunctional ependymal cells in $\mathrm{UBP}_{4} 3^{-/-}$mice, it is reasonable to hypothesise that any process, such as tissue repair or normal cell turnover, which utilizes cells derived from the ependymal layer, may be disrupted, resulting in the manifestation of various neurologic phenotypes that are currently attributed to hydrocephalus.

In conclusion, we have provided strong evidence that specific mammalian cells in vivo require the presence of UBP43 to remain viable. Dysfunction of such cells and their subsequent death, via necrosis, are likely consequent to increased intracellular levels of ISG15 conjugated proteins. Research is ongoing to identify the mo- 
lecular targets of ISG15 and fully elucidate the biological significance of protein ISGylation.

\section{Materials and methods}

Generation and genotyping of $\mathrm{UBP}^{-/-}$mice

A mouse genomic DNA fragment containing a $3.5-\mathrm{kb}$ upstream sequence and a 15-kb sequence of the UBP43 gene was cloned from a 129SV mouse genomic library (Stratagene) using UBP43 cDNA as a probe. To generate the upstream arm for homologous recombination from these sequences, a 2-kb fragment containing upstream intronic sequences and $100 \mathrm{bp}$ of exon 2 was isolated by Bcl I digestion. For downstream homologous recombination a $2.1-\mathrm{kb}$ fragment containing both intronic sequences and $50 \mathrm{bp}$ of exon 4 was prepared using Sal I digestion. Both fragments were then inserted into pBluescript (KS-) vector (Stratagene), which also contained $\beta$-galactosidase, neomycin, and thymidine kinase genes to construct the homologous replacement construct (Fig. 1a). This DNA was then linearised by Not I digestion and introduced, by electroporation, into R1 ES cells. Gene targeting into ES cell clones was determined by Southern blot analysis (Fig. 1a, probes A,B; data not shown) and germline transmitted chimeric mice produced using standard techniques. Mice homozygous for disruption of the UBP43 allele were then obtained by intercrossing F1 heterozygotes. Genotyping of resultant and successive 3-wk-old progeny was then achieved by isolation of tail DNA (by standard techniques) and Southern blot analysis. Briefly, $10 \mu \mathrm{g}$ of EcoR I digested mouse tail genomic DNA was separated on a $1 \%$ agarose gel, transferred to a nylon membrane (Hybond-N, Amersham), and hybridized with a complimentary random primer labeled probe $\left({ }^{32} \mathrm{P}\right)$ with detection via autoradiography.

\section{Histology}

For histology, wild-type and mutant littermates were deeply anaesthetized and transcardically perfused through the left ventricle with saline followed by $4 \%$ paraformaldehyde and $0.1 \%$ glutaraldehyde $(20 \mathrm{~mL})$ in phosphate-buffered saline (PBS) containing $2 \mathrm{mM} \mathrm{MgCl}_{2}(\mathrm{pH} 7.2)$ at $4^{\circ} \mathrm{C}$. Whole brains were then dissected free of the skull and fixation continued, by immersion, for a further hour at $4^{\circ} \mathrm{C}$ in the same fixative. Brains were then washed twice with PBS containing $2 \mathrm{mM} \mathrm{MgCl}_{2}$ and then cryopreserved overnight in $\mathrm{PBS} / 2 \mathrm{mM} \mathrm{MgCl}{ }_{2}$ containing $30 \%$ sucrose. The following morning brains were embedded in OCT freezing compound (TissueTek). Frozen sections were cut coronally (16 $\mu \mathrm{m})$ using a cryostat and placed on poly-L-lysine-coated SuperFrost microscope slides (Fisher Scientific). Sections were stored at $-80^{\circ} \mathrm{C}$ until required. For gross anatomical analysis, following perfusion fixation as described above, brains were sectioned sagitally and then photographed. For detailed histologic analysis 16 m frozen sections were stained with hematoxylin, dehydrated, and mounted using standard procedures. For immunohistochemistry, frozen sections were incubated with ISG15 antibody (a generous gift from Dr. E.C. Borden, The Cleveland Clinic Foundation, Cleveland, $\mathrm{OH}$ ) at a dilution of 1:100. Goat-anti-rabbit secondary antibodies (Alexa Fluor 488, Molecular Probes) were used at a dilution of 1:200. For detection of reporter gene expression frozen sections were incubated for $3 \mathrm{~h}$ at $37^{\circ} \mathrm{C}$ in staining solution containing X-gal (Sigma) at a concentration of $1 \mathrm{mg} / \mathrm{mL}$. Sections were then counterstained with nuclear fast red, dehydrated, and mounted using standard techniques. For ultrastructural studies 12 -d-old mice were perfused with $4 \%$ paraformaldehyde and $1.5 \%$ glutaraldehyde in phosphate buffer. Tissue blocks containing lateral ventricles were dissected from the brain and fixed in the same fixative for $24 \mathrm{~h}$ at $4^{\circ} \mathrm{C}$. Blocks were then postfixed in $1 \%$ osmium tetroxide, dehydrated, and embedded in EMbed 812/araldite mixture. Ultrathin sections $(\sim 70 \mathrm{~nm})$ were stained with uranyl acetate and lead citrate. Sections were viewed on a Phillips CM100 (FEI).

\section{Western blot}

To obtain protein extracts, adult mouse brain tissue or thymi (for verification of UBP43 deletion) were homogenized in ice-cold extraction buffer (20 mM Tris pH 7.5, 2 mM PMSF, 1\% Triton X-100, 2 mM $\beta$-mercaptoethanol, and a protease inhibitor cocktail; Sigma). Insoluble debris was removed by centrifugation. Twenty micrograms of each protein sample were then resolved on an 8-18\% gradient polyacrylamide gel for ISG15 blotting or a $10 \%$ polyacrylamide gel for UBP43 blotting. Confirmation of equal protein loading was gained by Ponceau staining of the gels. ISG15 conjugates were detected using $0.5 \mu \mathrm{g} / \mathrm{mL}$ of the primary antibody, while detection of UBP43 was achieved using a final antibody concentration of $0.1 \mathrm{\mu g} / \mathrm{mL}$. Bound antibodies were detected by HRP coupled goat anti-rabbit IgG.

\section{Acknowledgments}

We thank Ernest Butler for critical reading of the manuscript; the transgenic/ES cell core facility and electron microscopy core facility at The Scripps Research Institute for generating knockout mice and ultrastructural analysis, respectively; Carol Browne, Donald Yergeau, and Li-Qin Liu for technical assistance; Stuart Lipton and Dongxian Zhang for provision of histology facilities; Jiankun Cui for guidance in histologic techniques; Dr. Ernest Borden for ISG15 antibodies; and Dr. Iain Campbell, Dr. Charles D. Surh, Dr. Chad Kieper, and members of DEZ laboratory for valuable discussions. K.J.R. is supported by the Skaggs Postdoctoral Fellows program at The Scripps Research Institute. J.C.S. is supported by a grant from the ALSAM foundation and the Skaggs Institute for Research. DEZ is a Scholar of the Leukemia and Lymphoma Society. This work was supported by National Institutes of Health Grant CA79849. The Stein Endowment Fund has partially supported the departmental molecular biology service laboratory for DNA sequencing and oligonucleotide synthesis. This is manuscript \#14550-MEM from The Scripps Research Institute.

The publication costs of this article were defrayed in part by payment of page charges. This article must therefore be hereby marked "advertisement" in accordance with 18 USC section 1734 solely to indicate this fact.

\section{References}

Ahdab-Barmada, M., Moossy, J., Preble, O.T., and Youngner, J.S. 1982. Hydrocephalus in weanling mice induced by a temperature-sensitive mutant of vesicular stomatitis virus. J. Neuropathol. Exp. Neurol. 41: 606-617.

Barton, L.L. and Mets, J.B. 2001. Congenital lymphocytic choriomeningitis virus infection: Decade of rediscovery. Clin. Infect. Dis. 33: 370374.

Baumgartner, W.K., Krakowka, S., Koestner, A., and Evermann, J. 1982. Ultrastructural evaluation of the acute encephalitis and hydrocephalus in dogs caused by canine parainfluenza virus. Vet. Pathol. 19: 305-314.

Blomstrom, D.C., Fahey, D., Kutny, R., Korant, B.D., and Knight, E., Jr. 1986. Molecular characterization of the interferon-induced $15-\mathrm{kDa}$ protein. Molecular cloning and nucleotide and amino acid sequence. J. Biol. Chem. 261: 8811-8816.

D'Andrea, A. and Pellman, D. 1998. Deubiquitinating enzymes: A new class of biological regulators. Crit. Rev. Biochem. Mol. Biol. 33: 337352.

D’Cunha, J., Knight, E., Jr., Haas, A.L., Truitt, R.L., and Borden, E.C. 1996a. Immunoregulatory properties of ISG15, an interferon-induced cytokine. Proc. Natl. Acad. Sci. 93: 211-215.

D'Cunha, J., Ramanujam, S., Wagner, R.J., Witt, P.L., Knight, E., Jr., and Borden, E.C. 1996b. In vitro and in vivo secretion of human ISG15, an IFN-induced immunomodulatory cytokine. I. Immunol. 157: 41004108.

Farrell, P.J., Broeze, R.J., and Lengyel, P. 1979. Accumulation of an mRNA and protein in interferon-treated Ehrlich ascites tumour cells. Nature 279: 523-525.

Gilchrist, C.A. and Baker, R.T. 2000. Characterization of the ubiquitinspecific protease activity of the mouse/human Unp/Unph oncoprotein. Biochim. Biophys. Acta 1481: 297-309.

Haas, A.L., Ahrens, P., Bright, P.M., and Ankel, H. 1987. Interferon induces a 15-kilodalton protein exhibiting marked homology to ubiquitin. J. Biol. Chem. 262: 11315-11323.

Hicke, L. 2001. Protein regulation by monoubiquitin. Nat. Rev. Mol. Cell Biol. 2: 195-201.

Hochstrasser, M. 1996. Ubiquitin-dependent protein degradation. Annu. Rev. Genet. 30: 405-439.

. 2000. Evolution and function of ubiquitin-like protein-conjugation systems. Nat. Cell Biol. 2: E153-E157.

Jentsch, S. and Pyrowolakis, G. 2000. Ubiquitin and its kin: How close are the family ties? Trends Cell Biol. 10: 335-342.

Johansson, C.B., Momma, S., Clarke, D.L., Risling, M., Lendahl, U., and 
Frisen, J. 1999. Identification of a neural stem cell in the adult mammalian central nervous system. Cell 96: 25-34.

Johnson, R.T., Johnson, K.P., and Edmonds, C.J. 1967. Virus-induced hydrocephalus: Development of aqueductal stenosis in hamsters after mumps infection. Science 157: 1066-1067.

Kang, D., Jiang, H., Wu, Q., Pestka, S., and Fisher, P.B. 2001. Cloning and characterization of human ubiquitin-processing protease-43 from terminally differentiated human melanoma cells using a rapid subtraction hybridization protocol RaSH. Gene 267: 233-242.

Kawakami, T., Chiba, T., Suzuki, T., Iwai, K., Yamanaka, K., Minato, N., Suzuki, H., Shimbara, N., Hidaka, Y., Osaka, F., et al. 2001. NEDD8 recruits E2-ubiquitin to SCF E3 ligase. EMBO J. 20: 4003-4012.

Knight, E., Jr., Fahey, D., Cordova, B., Hillman, M., Kutny, R., Reich, N., and Blomstrom, D. 1988. A $15-\mathrm{kDa}$ interferon-induced protein is derived by $\mathrm{COOH}$-terminal processing of a $17-\mathrm{kDa}$ precursor. J. Biol. Chem. 263: 4520-4522.

Li, X.L., Blackford, J.A., Judge, C.S., Liu, M., Xiao, W., Kalvakolanu, D.V., and Hassel, B.A. 2000. RNase-L-dependent destabilization of interferon-induced mRNAs. A role for the 2-5A system in attenuation of the interferon response. J. Biol. Chem. 275: 8880-8888.

Lindeman, G.J., Dagnino, L., Gaubatz, S., Xu, Y., Bronson, R.T., Warren, H.B., and Livingston, D.M. 1998. A specific, nonproliferative role for E2F-5 in choroid plexus function revealed by gene targeting. Genes \& Dev. 12: 1092-1098.

Liu, L.Q., Ilaria, R., Jr., Kingsley, P.D., Iwama, A., van Etten, R.A., Palis, J., and Zhang, D.E. 1999. A novel ubiquitin-specific protease, UBP43, cloned from leukemia fusion protein AML1-ETO-expressing mice, functions in hematopoietic cell differentiation. Mol. Cell Biol. 19: 3029-3038.

Loeb, K.R. and Haas, A.L. 1992. The interferon-inducible 15-kDa ubiquitin homolog conjugates to intracellular proteins. I. Biol. Chem. 267: 7806-7813.

Lyapina, S., Cope, G., Shevchenko, A., Serino, G., Tsuge, T., Zhou, C., Wolf, D.A., Wei, N., Shevchenko, A., and Deshaies, R.J. 2001. Promotion of NEDD-CUL1 conjugate cleavage by COP9 signalosome. Science 292: 1382-1385.

Malakhov, M.P., Malakhova, O.A., Kim, K.I., Ritchie, K.J., and Zhang, D.E. 2002a. UBP43 (USP18) specifically removes ISG15 from conjugated proteins. J. Biol. Chem. 277: 9976-9981.

Malakhova, O., Malakhov, M., Hetherington, C., and Zhang, D.E. 2002b. Lipopolysaccharide activates the expression of ISG15-specific protease UBP43 via interferon regulatory factor 3. J. Biol. Chem. 277: 14703-14711.

McAllister, J.P. and Chovan, P. 1998. Neonatal hydrocephalus. Mechanisms and consequences. Neurosurg. Clin. N. Am. 9: 73-93.

Muller, S., Hoege, C., Pyrowolakis, G., and Jentsch, S. 2001. SUMO, ubiquitin's mysterious cousin. Nat. Rev. Mol. Cell Biol. 2: 202-210.

Pickart, C.M. 2001. Ubiquitin enters the new millennium. Mol. Cell 8: 499-504.

Raimondi, A.J., Clark, S.J., and McLone, D.G. 1976. Pathogenesis of aqueductal occlusion in congenital murine hydrocephalus. I. Neurosurg. 45: 66-77.

Rietze, R.L., Valcanis, H., Brooker, G.F., Thomas, T., Voss, A.K., and Bartlett, P.F. 2001. Purification of a pluripotent neural stem cell from the adult mouse brain. Nature 412: 736-739.

Sarnat, H.B. 1995. Ependymal reactions to injury. A review. I. Neuropathol. Exp. Neurol. 54: 1-15.

Schwartz, A.L. and Ciechanover, A. 1999. The ubiquitin-proteasome pathway and pathogenesis of human diseases. Annu. Rev. Med. 50: 57-74.

Schwechheimer, C., Serino, G., Callis, J., Crosby, W.L., Lyapina, S., Deshaies, R.J., Gray, W.M., Estelle, M., and Deng, X.W. 2001. Interactions of the COP9 signalosome with the E3 ubiquitin ligase SCFTIRI in mediating auxin response. Science 292: 1379-1382.

Schwer, H., Liu, L.Q., Zhou, L., Little, M.T., Pan, Z., Hetherington, C.J., and Zhang, D.E. 2000. Cloning and characterization of a novel human ubiquitin-specific protease, a homologue of murine UBP43 (Usp18). Genomics 65: 44-52.

Tardieu, M. and Weiner, H.L. 1982. Viral receptors on isolated murine and human ependymal cells. Science 215: 419-421.

Tateishi, K., Omata, M., Tanaka, K., and Chiba, T. 2001. The NEDD8 system is essential for cell cycle progression and morphogenetic pathway in mice. J. Cell Biol. 155: 571-579.
Wilkinson, K.D. 1997. Regulation of ubiquitin-dependent processes by deubiquitinating enzymes. FASEB J. 11: 1245-1256.

Yuan, W. and Krug, R.M. 2001. Influenza B virus NS1 protein inhibits conjugation of the interferon (IFN)-induced ubiquitin-like ISG15 protein. EMBO J. 20: 362-371.

Zhang, X., Shin, J., Molitor, T.W., Schook, L.B., and Rutherford, M.S. 1999. Molecular responses of macrophages to porcine reproductive and respiratory syndrome virus infection. Virology 262: 152-162. 


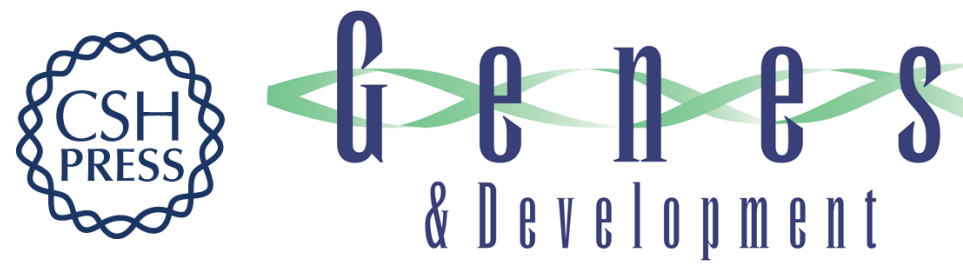

\section{Dysregulation of protein modification by ISG15 results in brain cell injury}

Kenneth J. Ritchie, Michael P. Malakhov, Christopher J. Hetherington, et al.

Genes Dev. 2002, 16:

Access the most recent version at doi:10.1101/gad.1010202

References This article cites 40 articles, 18 of which can be accessed free at: http://genesdev.cshlp.org/content/16/17/2207.full.html\#ref-list-1

License

Email Alerting

Receive free email alerts when new articles cite this article - sign up in the box at the top right Service corner of the article or click here.

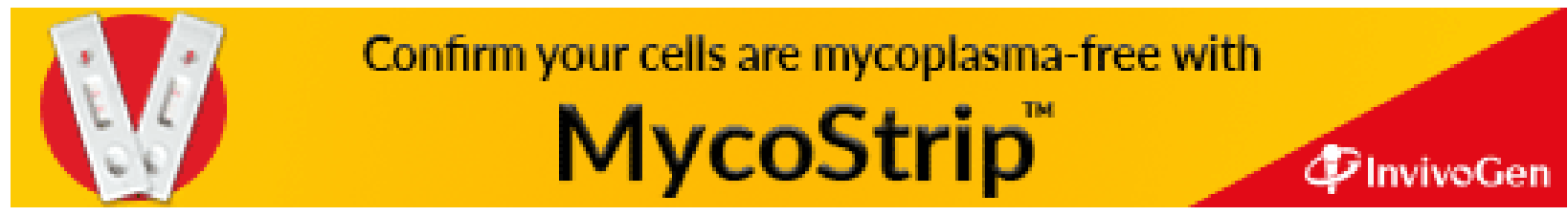

